\title{
Maximizing utilization of reactivated and left-over catalysts in heavy gas oil hydrotreater: A case study of ADNOC Refining
} \author{
Pierre Dufresne ${ }^{4}$, Stephane Morin ${ }^{1}$, and Mikael Berthod ${ }^{1}$ \\ ${ }^{1}$ ADNOC Refining Research Center, Abu Dhabi, United Arab Emirates \\ ${ }^{2}$ Albemarle, Dubai, United Arab Emirates \\ ${ }^{3}$ Al Bilad Catalyst, Jubail Industrial City, Kingdom of Saudi Arabia \\ ${ }^{4}$ Eurecat SA, La Voulte sur Rhône, France
}

Paco Laveille ${ }^{1, *}$, Abdul-Hamid Chaudhry ${ }^{1}$, Alessandro Riva ${ }^{2}$, Alain Salameh $^{3}$, Gnanapragasam Singaravel ${ }^{1}$,

Received: 22 January 2018 / Accepted: 27 August 2018

\begin{abstract}
Recently, ADNOC Refining Research Center (ARRC) has studied the possibility to maximize the reutilization of left-overs and reactivated hydrodesulfurization catalysts for one of its hydrotreater producing Ultra Low Sulfur Diesel (ULSD) from Heavy Gas Oil (HGO). Based on the refinery inventory, several catalyst configurations composed of different amounts of reactivated and fresh CoMo catalyst, including a full reactivated configuration having a stacked $\mathrm{CoMo} / \mathrm{NiMo} / \mathrm{CoMo}$ combination $(50 / 25 / 25)$, have been tested in a pilot-plant reactor under commercially-relevant conditions. Experimental results in terms of reactor bed temperature, $\mathrm{H}_{2}$ consumption, aromatics and diesel yields have been analyzed and compared to the current commercial hydrotreater load and catalyst supplier forecasts for the studied configurations. Results show excellent performances of reactivated catalysts and a strong effect of the NiMo layer in the case of the stacked configuration. In a pure CoMo configuration, up to $75 \%$ reactor volume of reactivated catalyst could be utilized without impacting the product quality and cycle length, compared to a full fresh CoMo catalyst load. The full reactivated stacked configuration performed even better than the full fresh CoMo catalyst, without impacting product quality and diesel yield. Potential effect of the reactivated catalysts on the reaction selectivity and the role of the NiMo layer in the stacked configuration are discussed. Pilot-plant experimental data were in strong accordance with catalyst supplier commercial forecasts, emphasizing the quality of the pilot-plant study. Implementation of one of the studied configuration by the refinery could lead to between $30 \%$ and $55 \%$ savings on the cost of catalyst for the next load.
\end{abstract}

\section{Introduction}

ADNOC Refining operates three refineries processing about 900000 bpsd. Overall, the different units (hydroprocessing, RFCC, reforming, gas cleaning and separation, etc.) involve more than 9000 MT of catalysts and adsorbents. Each material has to be carefully selected among the different commercial technologies and suppliers, targeting specific feed properties, process conditions and product quality. The purchase, shipment, and delivery processes of these materials as well as their life cycle have to be synchronized with the refineries planned turn-around time. Additionally, catalysts left-overs from unit loading accumulate in the warehouses and spent catalysts have to be disposed, recycled or reused $[1,2]$. Due to these complex movements of large catalyst volumes, a proper catalyst management has

\footnotetext{
* Corresponding author: plaveille@adnoc.ae
}

become a requirement for most refiners to improve their operation, catalysts inventory control, save cost, and eventually increase their profitability [3]. Catalyst management helps optimizing catalyst selection, purchase processes and adding value to spent and left-over catalysts by maximizing their reutilization or recycling them.

In ADNOC Refining, HydroDeSulfurization (HDS) catalysts represent more than $40 \%$ of catalyst inventory. HDS has become a major process mostly due to worldwide more stringent environmental policies pushing the production of 10 ppm sulfur diesels [4]. Organic sulfur compounds are also a strong poison of noble metal catalysts and therefore need to be removed from naphtha cuts prior to reforming process [5]. Each refinery feed contains a specific mixture of organic sulfur compounds and basically the heavier the molecule and the more hindered is the sulfur atom, the slower it reacts. Therefore, the increasing demand for pushing the limit of the bottom of the barrel conversion requires better performing and selective HDS catalyst to remove high level of recalcitrant sulfur [6]. 
To reduce sulfurs to ultra-low level $(<10 \mathrm{ppm})$, catalysts with very high HDS activity and the ability to handle different types of feed and conditions have to be designed. Most of the commercial catalysts are sulfided molybdenum promoted by cobalt (CoMoS) or nickel (NiMoS) supported on $\gamma-\mathrm{Al}_{2} \mathrm{O}_{3}$. Mo-S phase forms crystalline nano-sheets which may stack up onto each other. The catalytic activity comes mainly from $\mathrm{S}$ vacancies created at the edges of these nanostructures. Promoters such as $\mathrm{Co}$ and $\mathrm{Ni}$, which decorate the edges of the $\mathrm{MoS}_{2}$ planes, enhance the formation of $\mathrm{S}$ vacancies, and resulting catalytic performances [4]. There are two main chemical routes based on the accessibility of the sulfurs atom, from the organic reactant ("organic-sulfur"), to the active site of the catalyst. Compounds having easily accessible sulfurs typically follow a direct hydrogenolysis route (DDS), predominant with Co-promoted catalysts [7]. To remove sulfurs sterically hindered (e.g. 4-6 dimethyldibenzothiophene) the reaction goes first through the hydrogenation of a neighbor unsaturated $\mathrm{C}=\mathrm{C}$ bond followed by sulfur removal (HYD). The hydrogenation step is assumed to change the spatial orientation of the alkyl substituent, facilitating the sulfurs atom approach on the active site $[8,9]$. NiMo are known for their stronger HYD activity and are basically used with heavier feeds at higher hydrogen pressures. According to the latest findings, DDS pathway can happen at both "rim" and "brim" sites of the sulfided CoMo/NiMo nanostructures through a perpendicular $\sigma$ bond with the "organic-sulfur" atom [4, 10]. On the other hand HYD pathway (and hydrogenation), is restricted to the "brim" sites on top of the crystalline active phase with a horizontal $\pi$ interaction of the aromatic moiety with the surface plane. Several additional parameters such as the degree of MoS2 stacking, their promotion level with $\mathrm{Ni} / \mathrm{Co}$, their crystalline structure, their dispersion, and interaction with the support influence the final catalytic performances. It is generally admitted that "Type I" $\mathrm{MoS}_{2}$ structures active phase have a low stacking degree inducing strong interactions with the support via Mo-O-Al linkage. Consequently, those structures are often partially sulfided reducing their overall catalytic performances. Recent development in catalysts preparation allows a better control of the $\mathrm{MoS}_{2}$ crystalline phase. "Type II" active phase present significantly superior activity thanks to a higher stacking and sulfidation degree as well as an homogeneous dispersion of promoters at $\mathrm{MoS}_{2}$ edges. "Type II" catalysts are generally obtained by advanced synthesis methods using chelating ligand and/or specific thermal treatment/sulfidation programs [11, 12].

During the course of the process, catalysts are slowly deactivated by coke accumulation, active phase sintering, metal poisoning and loss of physical properties such as surface area or mechanical strength. Depending on the degree and nature of catalyst deactivation, refiners may consider reutilization, recycling or disposal of the spent catalysts $[1-3,13]$. Disposal, typically by landfilling, is usually considered the worst choice economically, as refiners have to pay $(\approx 5 \%$ of the catalysts load) to burry a potentially valuable material, and environmentally; it has been shown that metal could leach out the catalysts and pollute soils and underground waters. Recycling, meaning recovering the

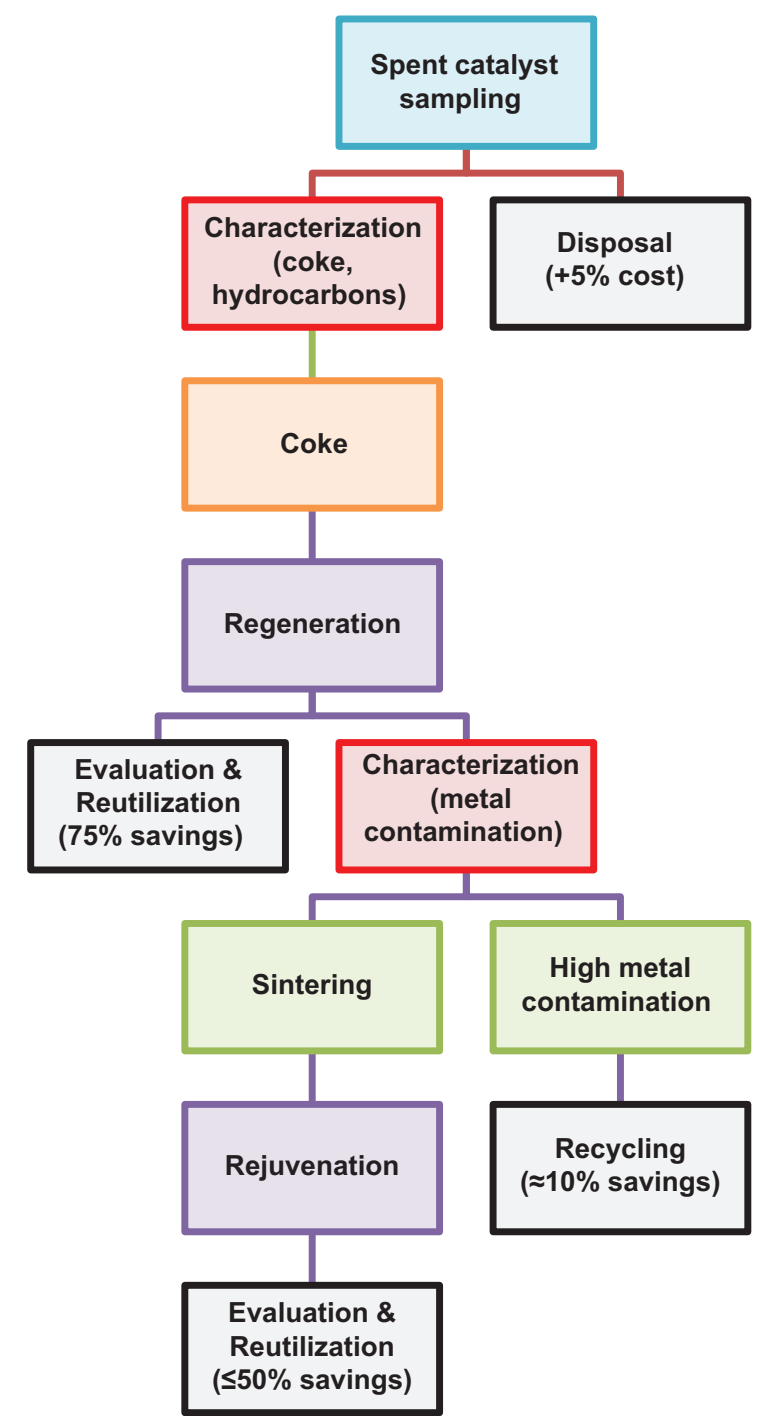

Fig. 1. Scheme presenting the general process to assess spent HDS catalyst management.

metals to sell them, can bring savings in the range of $5-10 \%$ of the fresh catalyst load value but is subject to the market appreciations for the individual metals. On the other hand, reutilization of the spent catalyst after proper regeneration/reactivation, can cost 50-75\% less than a load of fresh catalyst. As depicted in Figure 1, to decide on the best management of the spent catalyst it is mandatory to understand the cause of catalyst deactivation through its detailed physico-chemical characterization. Deactivation by residual carbon accumulated on the surface of the catalyst (coke) and blocking the access to the active sites, can be addressed by a simple regeneration process (combustion under a flow of hot air) (Fig. 2). Some sintering could also occur, i.e. metals aggregation reducing the total number of active sites. In that case, a more advanced "rejuvenation" technology is required. Catalyst manufacturers have developed the latter especially for "Type II" HDS catalysts, to recover a degree of active phase dispersion similar to the fresh catalyst. 

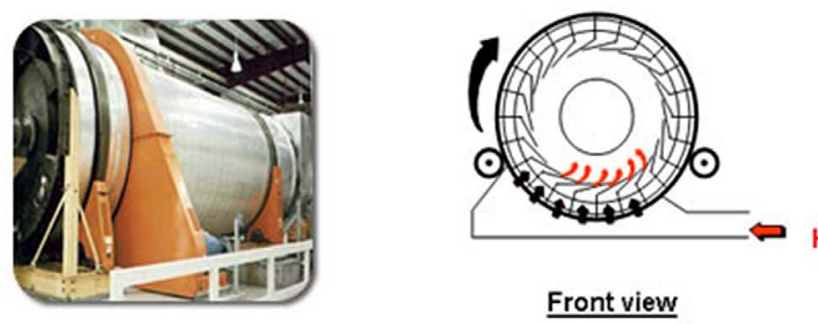

Roto-louvre Oven

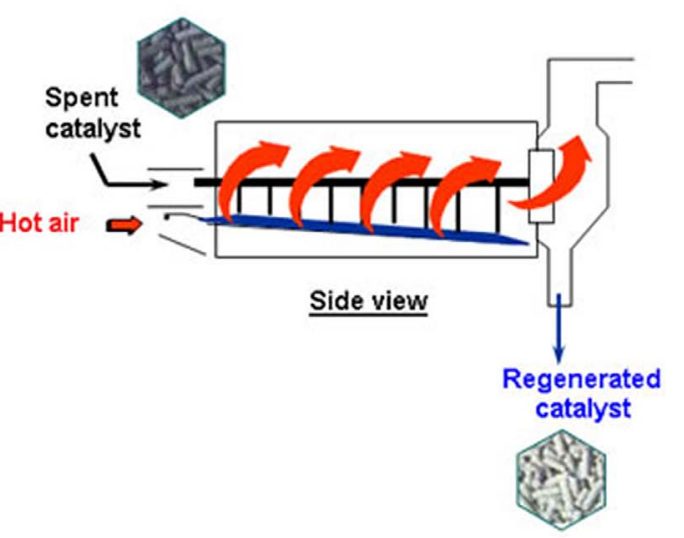

Fig. 2. Picture and scheme of the industrial oven used by Al Bilad Catalyst to regenerate HDS catalysts.

The concept behind it is to impregnate the catalyst with solutions containing at least chelating agents (e.g. organic acids) that dissolve the metallic phase and thus redisperse it on the support. On the other hand, high levels of metals contamination, typically from processing heavy vacuum gas oils, and physical damages to the catalyst, resulting of process upsets, are considered irreversible and would guide the choice toward recycling. If spent catalyst reutilization is targeted, it is also essential to evaluate the activity recovery under commercially relevant conditions and assess whether the reactivated catalyst can be reutilized in the same unit it comes from, under the same feed and process conditions, if the activity loss has to be balanced with some amount of fresh catalyst, or if it has to be reutilized in a different unit processing a less severe feed.

This article presents a spent HDS catalyst management case study of ADNOC Refining. The main target was to maximize utilization of left-over and reactivated catalysts inventory while keeping product quality and cycle length similar to a reactor fully loaded with fresh catalyst. Pilot plant experimental data were compared to the catalyst supplier forecasts and detailed liquid product analysis has been performed.

\section{Materials, methods and study background}

\subsection{Catalyst}

All the catalysts studied belong to Albemarle's STARS ${ }^{\circledR}$ portfolio. STARS ${ }^{\circledR}$ catalysts are advertised by Albemarle Corporation as the first 100\% Type II catalyst delivered on the market following a collaboration with Nippon Ketjen Corporation Ltd [14]. In this communication catalysts will be denominated CoMo or NiMo based on their metal composition. The number 1 or 2 (CoMo-1, CoMo-2) refers to the $\mathrm{STARS}^{\circledR}$ generation, the higher the newer. Finally the letter "R" (CoMo-1R, NiMo-1R) will be added when the catalyst has been reactivated.

The reactivation (regeneration + rejuvenation) has been carried out by $A l$ Bilad Catalyst Company (Saudi
Arabia), a joint venture between Eurecat SA and Gulf Country Council (GCC). Al Bilad Catalyst and Eurecat are companies active in spent catalysts activity recovery and metals recycling. The reactivation comprises an oxidative regeneration step followed by Albemarle's proprietary rejuvenation technology, REACT ${ }^{\mathrm{TM}}$. Following the rejuvenation, Al Bilad Catalyst evaluate the activity comparing the catalytic performances of the reactivated catalyst to the fresh counterpart under standard conditions (LGO, $\mathrm{LHSV}=2 \mathrm{~h}^{-1}, \quad P=40$ bar, $\mathrm{H}_{2} / \mathrm{HC}=300, \quad T=357$, $362{ }^{\circ} \mathrm{C}$ and $367^{\circ} \mathrm{C}$ ). Relative Volume Activity is estimated at each temperature by the ratio of rate constants, $\mathrm{RVA}=\left(k_{\mathrm{v}} / k_{\mathrm{vref}}\right) \times 100 \quad$ where $\quad k_{\mathrm{v}}=1 / \mathrm{S}_{\mathrm{o}}(1 / n-1)$ $\left(\left(1 / \mathrm{S}^{n-1}\right)-\left(\mathrm{S}_{\mathrm{o}}{ }^{n-1}\right)\right) \mathrm{LHSV}$.

\subsection{Pilot plant tests}

Four catalyst combinations with different amounts of CoMo-2, CoMo-1R and NiMo-1R have been tested using a Zeton pilot-plant operating two trains in parallel (Fig. 3). Each train is composed of two isothermal fixed bed reactors in series, each loaded with $20 \mathrm{~mL}$ of catalyst, and operated in a down flow mode. The reactor effluent passes through a High Pressure (HP) separator followed by a Low Pressure (LP) separator that integrates a $\mathrm{N}_{2}$ stripper $(80 \mathrm{~mL} / \mathrm{min})$. The gas phase obtained in the top portion of the HP separator is diverted to an online Refinery Gas Analyzer (RGA) during the test period. The stripped liquid sample is further analyzed off-line.

Pilot-plant experiments were conducted with conditions the most commercially-relevant for the refinery. The test feed was Heavy Gas Oil (HGO) obtained from Ruwais refinery, one of the refinery operated by ADNOC Refining. It is the most severe feed the commercial hydrotreater is likely to process. The HGO properties are presented in Table 1. Process conditions of the commercial units have been applied to the pilot plant: Liquid Hourly Space Velocity $(\mathrm{LHSV})=0.64 \mathrm{~h}^{-1}(100 \%$ capacity $), \mathrm{P}=\mathrm{Pp}\left(\mathrm{H}_{2}\right) \times$ $\mathrm{H}_{2}$ purity $=55.7$ bar, $\mathrm{H}_{2} / \mathrm{Oil}=300.40 \mathrm{~mL}$ of each catalyst (2 reactors of $20 \mathrm{~mL}$ in series) have been loaded taking into account their individual density measured with a 


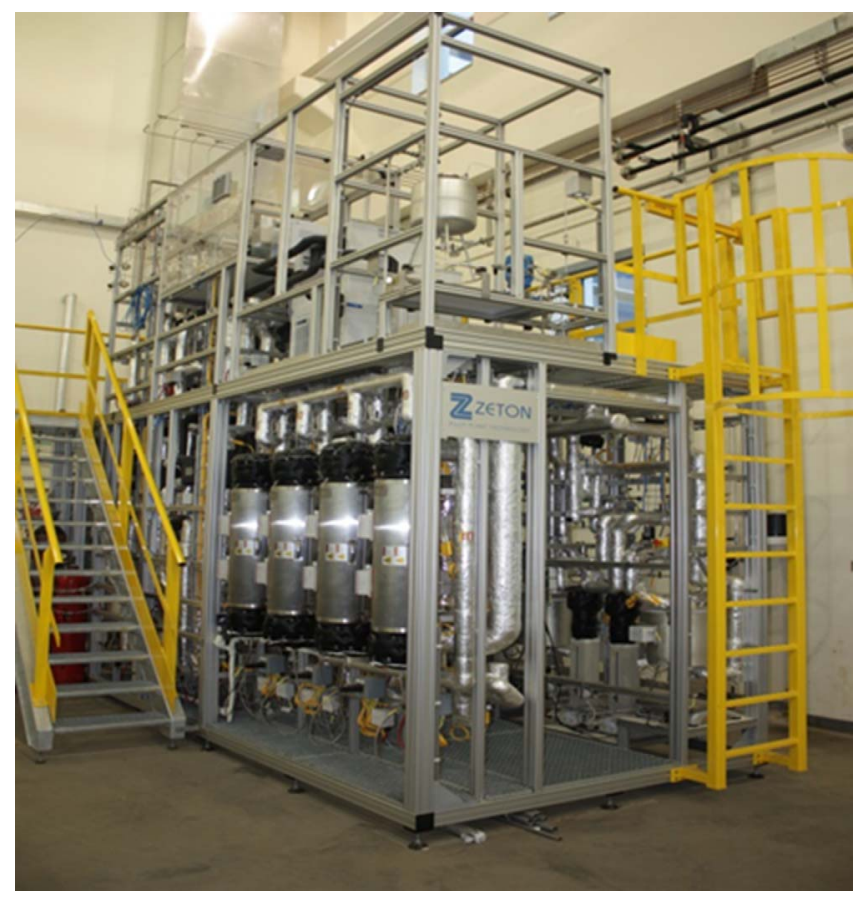

Fig. 3. TRC's Pilot plant hydrotreater used in this study.

Micromeritics GeoPyc 1360 automated tap density analyzer (chamber diameter $=50.8 \mathrm{~mm}, F=40 \mathrm{~N}, 7$ cycles per analysis). Catalysts have been sulphided in situ with Dimethyl Disulfide (DMDS) as per vendor recommendations. The reactors are stabilized about $10^{\circ} \mathrm{C}$ below expected Start Of Run (SOR) temperature under feed and process conditions described above. Temperature is then adjusted stepwise (3-4 test points) until reaching about $10 \mathrm{ppm}$ sulfur in the liquid product. Stability of test point is confirmed when sulfur analysis present a standard deviation $<10 \%$ over 3 days. Rate constant for each test point is calculated using $n$th $(n=1.4)$ reaction order rate equation $\left(k=\left(X_{\mathrm{i}}^{(1-n)}-X_{\mathrm{f}}^{(1-n)}\right) /((1-n)\right.$ LHSV $\left.)\right)$ and used to plot Arrhenius equation.

\subsection{Analysis}

Total sulfur, total nitrogen and liquid density analysis have been performed twice a day on pilot-plant liquid samples in order to validate stable catalyst performances as described above. Gases are analyzed by-online gas chromatography at time of liquid sampling. Detailed product analysis, including total sulfur and nitrogen analysis, density, distillation (D86), simulated distillation, H-NMR and aromatic distribution, have been performed when reaching $10 \mathrm{ppm}$ sulfur conditions in order to calculate mass balance, precise $\mathrm{H}_{2}$ consumption, and yields. $\mathrm{H}_{2}$ consumption is calculated by differential H-NMR analysis between feed and product at $10 \mathrm{ppm}$ sulfur, adding $\mathrm{H}_{2}$ consumed by sulfur $\left(\mathrm{H}_{2} \mathrm{~S}\right)$, nitrogen $\left(\mathrm{NH}_{3}\right)$ and cracked products $\left(\mathrm{CH}_{x}\right)$. Distillate yield is calculated from D86 distillation fraction above $135^{\circ} \mathrm{C}$. The standard methods and equipment used for each analysis are summarized in Table 2.
Table 1. Test feed (HGO) properties.

\begin{tabular}{lc}
\hline Feed property & Value \\
\hline Total acid number $(\mathrm{mgKOH} / \mathrm{g})$ & 0.023 \\
Total aromatics $(\mathrm{wt} \%)$ & 26.9 \\
Mono-aromatics $(\mathrm{wt} \%)$ & 15.1 \\
Di-aromatics $(\mathrm{wt} \%)$ & 9.7 \\
Tri $(+)$ aromatics $(\mathrm{wt} \%)$ & 2.1 \\
Carbon (wt\%) & 86.2 \\
Hydrogen H-NMR $(\mathrm{wt} \%)$ & 13.12 \\
Cloud point $\left({ }^{\circ} \mathrm{C}\right)$ & 14.4 \\
Density $(\mathrm{Kg} / \mathrm{L})$ & 0.8603 \\
IBP D86 $\left({ }^{\circ} \mathrm{C}\right)$ & 212.4 \\
FBP D86 $\left({ }^{\circ} \mathrm{C}\right)$ & 392.3 \\
Loss D86 vol\% & 0.8 \\
$5 \%$ recovery D86 $\left({ }^{\circ} \mathrm{C}\right)$ & 281.4 \\
10\% recovery D86 $\left({ }^{\circ} \mathrm{C}\right)$ & 297.7 \\
20\% recovery D86 $\left({ }^{\circ} \mathrm{C}\right)$ & 314 \\
$30 \%$ recovery D86 $\left({ }^{\circ} \mathrm{C}\right)$ & 322.4 \\
$40 \%$ recovery D86 $\left({ }^{\circ} \mathrm{C}\right)$ & 330.2 \\
$50 \%$ recovery D86 $\left({ }^{\circ} \mathrm{C}\right)$ & 336.8 \\
$60 \%$ recovery D86 $\left({ }^{\circ} \mathrm{C}\right)$ & 343.4 \\
$70 \%$ recovery D86 $\left({ }^{\circ} \mathrm{C}\right)$ & 350.8 \\
$80 \%$ recovery D86 $\left({ }^{\circ} \mathrm{C}\right)$ & 360.1 \\
$90 \%$ recovery D86 $\left({ }^{\circ} \mathrm{C}\right)$ & 374.0 \\
$95 \%$ recovery D86 $\left({ }^{\circ} \mathrm{C}\right)$ & 387.9 \\
Flash point $\left({ }^{\circ} \mathrm{C}\right)$ & 102.5 \\
Pour point $\left({ }^{\circ} \mathrm{C}\right)$ & 15 \\
Total sulfur $(\mathrm{ppm})$ & 9654 \\
Total nitrogens $(\mathrm{ppm})$ & 185 \\
\hline
\end{tabular}

\section{Results and discussion}

Lately ADNOC Refining unloaded 100 MT of spent CoMo1 catalyst from a hydrotreater processing LGO and HGO to $10 \mathrm{ppm}$ sulfur diesel. Two samples, one from each bed of the commercial unit, have been sent to Al Bilad Catalyst (ABC) for activity recovery assessment. A summary of the physicochemical analysis results obtained by $\mathrm{ABC}$ is presented in Table 3. After the oxidative regeneration step, 98-99\% of carbon and $95 \%$ of sulfur are removed on both samples. Analysis of metals and physical properties does not show significant irreversible contamination or loss of physical properties. Therefore following the regeneration step a composite sample has been prepared (mixture of beds 1 and 2) and sent to the rejuvenation process. Albemarle proprietary rejuvenation technology $\left(\mathrm{REACT}^{\circledR}\right)$ targets the re-dispersion of the sintered active phase of the regenerated catalyst to "Type II" structures. Each catalyst manufacturer has developed its own rejuvenation technology dedicated to their "Type II" catalyst chemistry. Rejuvenation is particularly important for "Type II" HDS catalysts, as the regeneration step addresses only coke deactivation and will only allow the recovery of maximum $90 \%$ of the fresh "Type II" catalyst 
Table 2. Analyses, methods and equipment used in this study to follow pilot-plant experiments.

\begin{tabular}{lcl}
\hline Analysis & Method & \multicolumn{1}{c}{ Equipment } \\
\hline Total sulfurs $(>15 \mathrm{ppm})$ & ASTM D4294 & Oxford x-superme8000 EDXRF \\
Total sulfurs $(<15 \mathrm{ppm})$ & ASTM D5453 & Antek 9000 UVF \\
Total nitrogen & ASTM D4629 & Antek Multitek UVF analyzer \\
Density & ASTM D4052 & Anton Paar DMA 4500M \\
Simulated distillation & ASTM D2887 & Agilent 7890A GC-FID \\
Distillation & ASTM D86 & Normalab NDI 440 \\
H-NMR & ASTM D7171 & Bruker m920 \\
Aromatic speciation & ASTM D6591 \& IP 391 & Agilent 1260 infinity HPLC-UV \\
Sulfurs speciation & ASTM D5623 & PerkinElmer clarus 580 GC-SCD \\
\hline
\end{tabular}

Table 3. Summary of physico-chemical analysis performed by Al Bilad Catalyst on the two CoMo-1 catalysts samples drawn from the commercial unit, before (spent) and after regeneration step (Lab regenerated).

\begin{tabular}{llccc}
\hline Type & \multicolumn{1}{c}{ Analysis } & Sample bed 1 & Sample bed 2 & Composite (bed 1 bed 2) \\
\hline Spent & Hydrocarbon (wt\%) & 0 & 0 & 0 \\
& Carbon (wt\%) & 6.0 & 9.2 & 7.5 \\
& Sulfur (wt\%) & 11.9 & 11.4 & 11.7 \\
Regenerated & Carbon (wt\%) & 0.1 & 0.1 & 0.1 \\
& Sulfur (wt\%) & 0.6 & 0.7 & 0.6 \\
& Surface area $\left(\mathrm{m}^{2} / \mathrm{g}\right)$ & 161 & 164 & 162 \\
& Av. length (mm) & 3.7 & 3.9 & 3.9 \\
BCS (MPa) & 1.4 & 1.3 & $<0.01$ \\
& As (wt\%) & $<0.01$ & $<0.01$ & $<0.01$ \\
& V (wt\%) & 0.02 & 0.01 & 0.07 \\
Fe (wt\%) & 0.15 & 0.05 & 0.09 \\
Si (wt\%) & 0.16 & 0.07 & $<0.05$ \\
& Na (wt\%) & $<0.05$ & $<0.05$ & \\
\hline
\end{tabular}

activity. The remaining of the catalytic performances is attributed to the deactivation by sintering of the active phase resulting in a loss of "Type II" nanostructures. As it can be observed on the STEM-EDX mapping of a "Type II" CoMo catalyst (Fig. 4), the rejuvenation process has a clear effect on the dispersion of Mo and Co nano-structures. The active phase aggregates observed after regeneration are completely gone following the rejuvenation step. Similar observation can be made on HR-TEM images (Fig. 5). According to the technology provider, up to $99 \%$ of the original volume activity can be recovered and thanks to its minor impact on catalyst's mechanical properties, REACT $^{\mathrm{TM}}$ can be applied up to 3 or 4 times on the same catalyst. In the case of the CoMo-1 used for this study, Al Bilad Catalyst estimated an activity recovery of $99 \%$ (RVA) following a pilot-plant evaluation under standard conditions as described in material and methods.

Following the activity recovery assessment by Al Bilad Catalyst, ADNOC Refining decided to reactivate the full batch of spent CoMo-1 (>100 MT). Even though Al Bilad Catalyst estimated an RVA of $99 \%$ indicating a successful reactivation, this value being obtained from standard conditions, a detailed study, under commercially relevant conditions was essential to assess whether the reactivated CoMo-1R catalyst could be reutilized in the same commercial unit it came from, processing the same feed and achieving the same yields and product quality targets that of the fresh counterpart. The main target was to reduce the cost of the catalyst load by maximizing reutilization of the spent-reactivated catalysts without compromising on the refinery production targets: $10 \mathrm{ppm}[\mathrm{S}]$ Ultra Low Sulfur Diesel (ULSD), $\geq 48$ months cycle length, similar distillate yields and aromatic content. Considering that part of the reactivated CoMo-1R had already be reused in another unit of the refinery, and the remaining inventory could only fill $75 \%$ of the hydrotreater reactor volume, the question of which catalyst to balance the reactor volume and how it would impact the overall performances of the hydrotreater was part of the study. In the refinery warehouse, left-overs of CoMo-2, a newer STARS ${ }^{\circledR}$ generation currently in use in the hydrotreater, representing $5 \%$ of the reactor volume, could be used to complete the load. In addition, a reactivated NiMo catalysts (NiMo-1R) coming from a different unit, a VGO hydrotreater, was available in large quantities. This catalyst was also part of Albemarle STARS ${ }^{\circledR}$ portfolio, reactivated by Al Bilad 

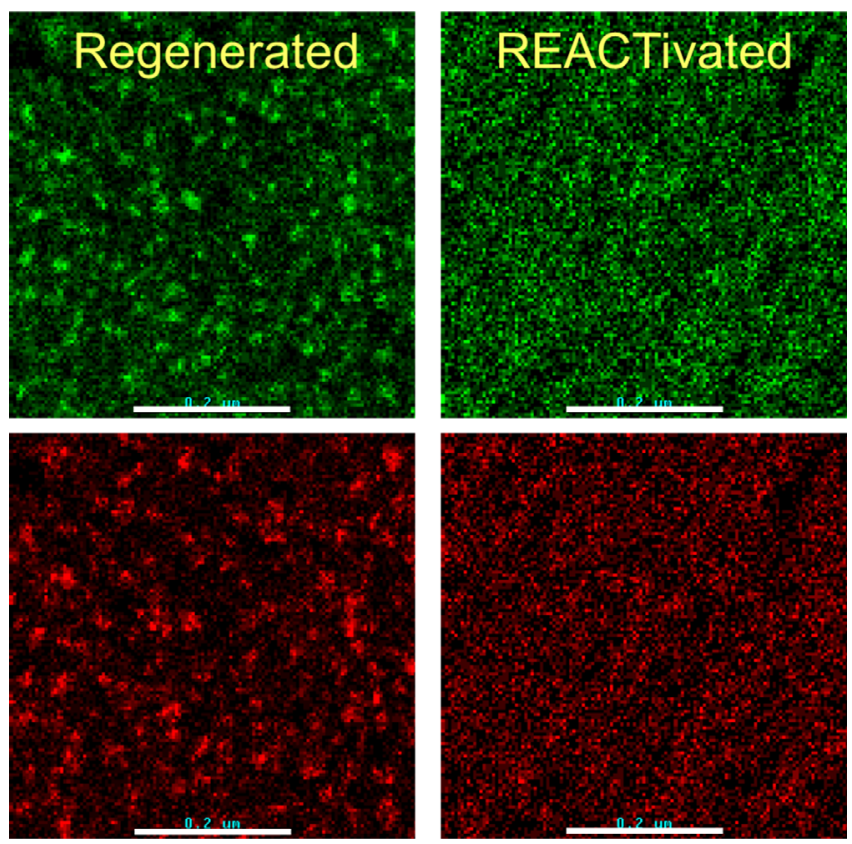

Fig. 4. STEM-EDX mapping images of molybdenum (green) and cobalt (red) phases of a CoMo Type II STARS $\mathrm{B}_{\circledast}$ catalyst after simple regeneration (left) and $\mathrm{REACT}^{\mathrm{TM}}$ rejuvenation (right), showing the recovery of the active phase dispersion after $\mathrm{REACT}^{\mathrm{TM}}$ process. Scale bar is $200 \mathrm{~nm}$. Data provided by Albemarle.

Catalyst following the same procedure as described above, with an RVA estimated at $95 \%$.

Keeping in mind the goal of maximizing the utilization of those reactivated and left-over catalysts without compromising on the product quality, yield and cycle length, ARRC has evaluated the performances of different catalysts configurations under pilot-plant conditions similar to the commercial hydrotreater. The different configurations are depicted in Figure 6. The first configuration (Ref, $100 \%$ CoMo-2) corresponds to the actual load of the commercial unit and is used as a reference to compare the performances of the other catalyst combinations to what is currently achieved in the refinery. Combinations \#1 and \#2 have different amounts of reactivated catalyst, respectively, $50 \%$ and $75 \%$ of CoMo-1R, completed by the fresh CoMo- 2 . The last configuration (\#3) is composed fully of reactivated catalyst, CoMo-1R/NiMo-1R/CoMo-1R (50/25/25). This specific stacked configuration is also proposed by Albemarle as part of their kinetic and reactor loading optimization, under the commercial name $\mathrm{STAX}^{\circledR}$

The pilot-plant experimental conditions are described in the material and method part and were selected to simulate the commercial hydrotreater settings. For each catalyst combination, reactor temperature at $10 \mathrm{ppm}$ sulfur is calculated back from Arrhenius equation for each combination and compared to the reference reactor (current load in the commercial unit, Fig. 7, blue histograms). Experimental results show excellent catalytic performances of reactivated CoMo-1R compared to fresh CoMo-2. As it can be seen in Figure 7, no temperature difference could be observed when having $50 \%$ CoMo-1R in combination with CoMo-2 (configuration $\# 1$ ), compared to the reference reactor (full fresh CoMo-2). The configuration \#2, having $75 \%$ CoMo- $1 \mathrm{R}$ and $25 \%$ CoMo-2, led only to $1{ }^{\circ} \mathrm{C}$ higher reactor temperature than the reference reactor. These results confirm that reactivated CoMo- $1 \mathrm{R}$ has recovered most of its initial activity. This is in agreement with the RVA value (99\%) provided by Al Bilad Catalyst. Even more interesting is the performances of the stacked CoMo-1R/NiMo-1R/ CoMo-1R configuration (\#3). This full reactivated catalyst combination performs $2{ }^{\circ} \mathrm{C}$ better than the full fresh CoMo-2 reference. When comparing configuration \#2 and $\# 3$, where the $25 \%$ reactor volume of fresh CoMo-2 is replaced by the same amount of reactivated NiMo-1R, $3{ }^{\circ} \mathrm{C}$ is gained. This shows how the NiMo1-R layer, even though it presents a lower RVA than the reactivated CoMo-1R (95\% vs. 99\%), has a strong effect on the overall reactor performances. NiMo is known to have a higher catalytic activity against bulky organic sulfurs and nitrogen, thanks to its higher HYD pathway [4, 7]. The benefit of a stacked configuration and the exact role of the NiMo layer will be discussed later. The lower RVA for NiMo catalyst can be explained by the more severe feed (VGO) the NiMo catalyst processed before being reactivated. VGO typically contain higher amount of poisoning metals such as V, As, Si, which accumulate in the pores of the catalyst support and are not removed during the rejuvenation process $[11,15]$.

In parallel to the pilot-plant study, ARRC has requested the catalyst provider, Albemarle, to provide their SOR WABT prediction for each of the studied catalyst combination. Those data are obtained using a model simulating the behavior of the catalysts in similar commercial conditions. When comparing the pilot-plant experimental results with Albemarle commercial forecasts (Fig. 7), very similar trend can be observed. For each catalyst configuration, Albemarle consistently predicts $\triangle \mathrm{WABT} 1^{\circ} \mathrm{C}$ higher than our experimental data. This strongly supports the quality of the pilot-plant test and related results and discussion. Besides, pilot plant experimental results may vary from commercial unit data due to differences in parameters such as reactor hydrodynamic, hardware parts (distribution tray, quenching zone) or grading beds not taken into considerations in pilot-plant studies. Consequently, when comparing catalyst performances in pilot-plants, it makes more sense to report temperature variations $(\Delta T)$ compared to a reference than absolute reactor temperature values $[16,17]$.

Concerning cycle-length estimation, the pilot plant study was not designed to measure deactivation rates experimentally for each catalyst combination. Accurate measurement of HDS catalyst deactivation rate under commercially-relevant conditions is not straightforward and usually required performance testing for extended period of time as the values are in the range of $1^{\circ} \mathrm{C} /$ month. Different protocols have been reported to accelerate HDS catalysts deactivation in order to understand the deactivation mechanisms and kinetics, but the conditions are usually far from the commercial unit's [18-20]. Therefore in order to estimate the cycle length of the different catalyst combination presented in this study, values provided by 

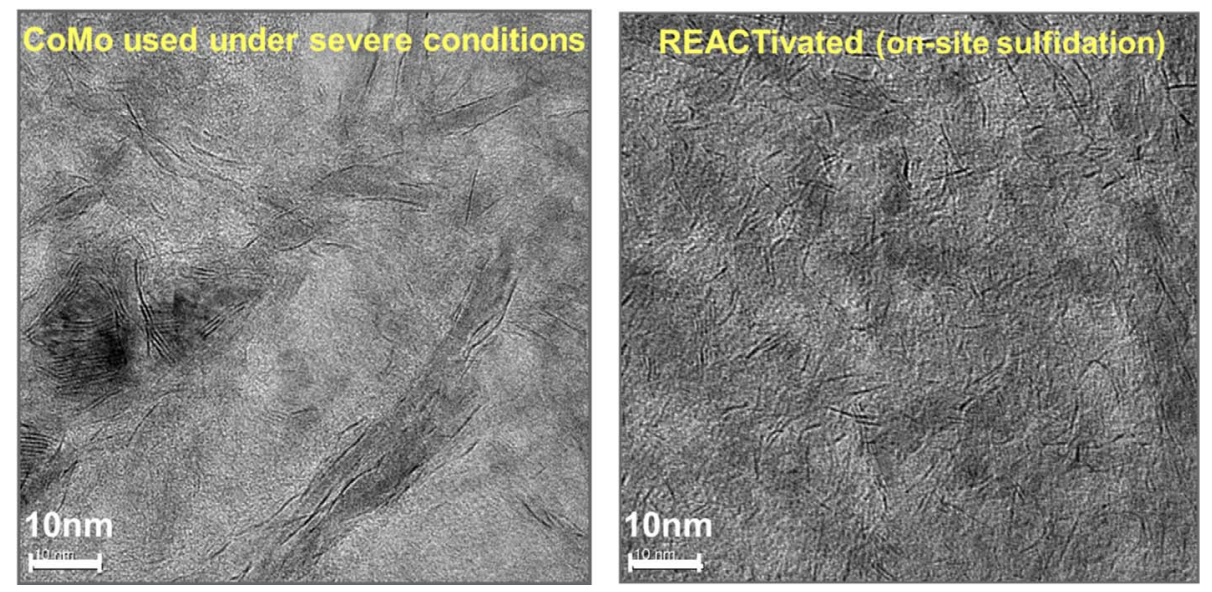

Fig. 5. HR-TEM picture of CoMo phase dispersion (black lines) on a spent catalyst (left) and after reactivation, showing the re-dispersion of the active phase after $\mathrm{REACT}^{\circledR}$ process. Data provided by Albemarle.

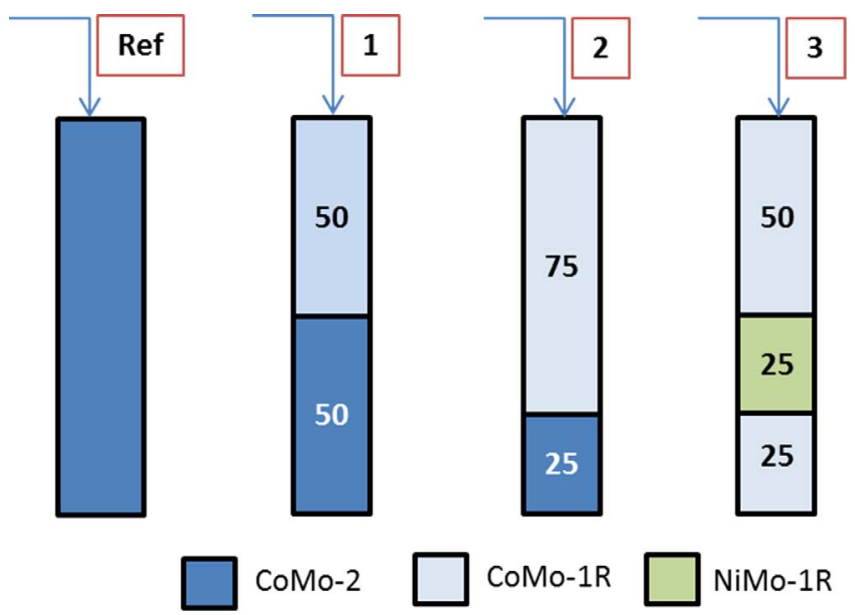

Fig. 6. Scheme showing the different catalyst configuration studied. Values in the colored boxes indicate the vol\% of the reactor.

the catalyst supplier for the fresh CoMo-2 (reference configuration) have been applied to the modified operating window of the different scenarios. For CoMo-2, a maximum cycle length of 53 months, with a deactivation rate of $0.9^{\circ} \mathrm{C} /$ months, has been predicted by Albemarle and confirmed by the refinery. Using those figures in the case of the least performing combination, (\#2, 75\% CoMo-1R, $25 \%$ CoMo-2), cycle length is expected to be 1 or 2 months shorter than the reference reactor, still providing the desired performances at $100 \%$ commercial unit capacity for about 51 months. Therefore it is clear that all of the catalyst combinations will perform above the target of 48 months requested by the refinery.

As discussed above, reactivated catalysts may not fully resemble their fresh counterparts. Remaining metal contaminants, structural defects (loss of porosity, surfaces, mechanical strength, etc.) or the ratio between Type I and Type II active phase following the rejuvenation process may affect their selectivity for HDS. Side reactions, mostly hydrogenation and to a lower extend cracking [21], could

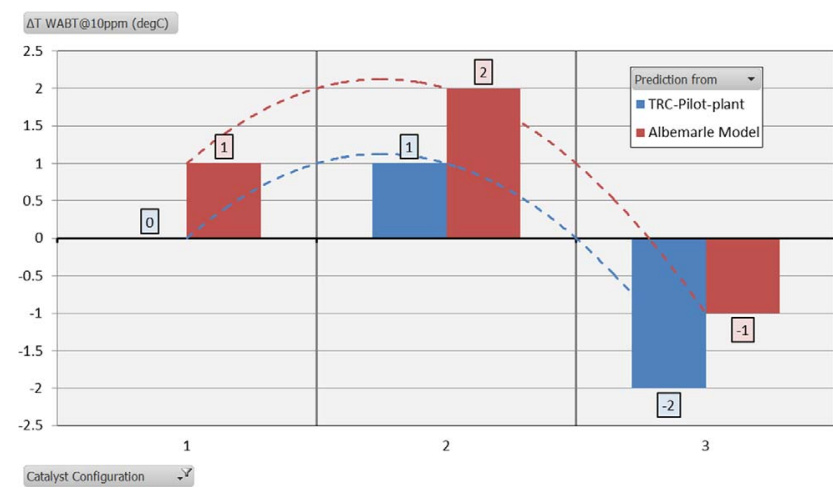

Fig. 7. TRC pilot plant results and Albemarle forecast for the different catalyst configuration in terms of reactor temperature differences compared to the reference (current commercial unit load).

modify the final product "quality" and overall refinery profitability. In order to verify that large quantities of reactivated catalyst do not alter the diesel qualities, yields and $\mathrm{H}_{2}$ consumption, detailed analysis of the liquid and gas products have been performed for each catalyst configuration when reaching $10 \mathrm{ppm}$ sulfur conditions (Tab. 4, Fig. 8). Product density is a good parameter to observe differences in catalysts behavior as it varies accordingly to the hydrocarbon composition of the product [22]. The density values measured for all the tested configurations are very similar $(0.8400 \mathrm{~kg} / \mathrm{L} \pm 0.001)$ suggesting no obvious variation in the reactivated catalyst activity. In this study, a slight difference of distillate yield $(-0.6 \%)$ is measured between the reference combination (fresh CoMo-2) and the reactors containing reactivated catalysts. However combinations $\# 1, \# 2$, and $\# 3$, having respectively 50, 75 and $100 \mathrm{vol} \%$ reactivated catalyst, present similar distillate yields $(95.9 \% \pm 0.1)$. Therefore the reactivated catalyst does not seem to unbalance excessively the reaction selectivity. Mono-aromatics are important components of the diesel cuts, participating to their ignition and combustion profile 
Table 4. Comparison of liquid product properties at $10 \mathrm{ppm}[\mathrm{S}]$ for the different catalyst combination studied.

\begin{tabular}{lcccc}
\hline Product parameter & Ref & $\# 1$ & $\# 2$ & $\# 3$ \\
\hline Diesel yield (\%) & 96.5 & 95.9 & 95.9 & 96 \\
Density $(\mathrm{Kg} / \mathrm{L})$ & 0.8390 & 0.8405 & 0.8407 & 0.8400 \\
$\mathrm{H}_{2}$ consumption $(\mathrm{l} / \mathrm{l})$ & 40 & 39.8 & 40.1 & 39.8 \\
\hline
\end{tabular}

[23]. On the other hand polycyclic-aromatics are considered carcinogenic molecules and they are the main source of atmospheric soot coming from their uncompleted combustion in diesel engines. In most of the studies aromatics are reported to be strong inhibitor of the HYD pathway [4]. During HDS, (poly)aromatics are saturated sequentially and therefore their final content and distribution are strongly dependent on the catalyst hydrogenation activity. Aromatic analysis of the feed and the products at $10 \mathrm{ppm}[\mathrm{S}]$ of the different catalysts configurations are presented in Figure 8. The total aromatic content, and decrease in poly-aromatics species, can be clearly observed when comparing the diesel products to the feed. There is also a noticeable difference between the product of the reference reactor and the combinations containing the reactivated catalysts. The content for each measured aromatic values (total, mono, di, tri + and poly) is about $5-10 \%$ lower in presence of a reactivated catalyst. However, no clear trend is observed between the products of the reactors having various amount of reactivated catalyst. It could be expected that the configuration made of $100 \%$ reactivated catalyst, including $25 \%$ of NiMo, known for its higher [HYD] activity, would present significantly less aromatics that the others configurations, but this is not observed in our analysis. To confirm this point, $\mathrm{H}_{2}$ consumptions have been calculated from H-NMR analysis of the liquid products, taking into account $\mathrm{H}_{2} \mathrm{~S}, \mathrm{NH}_{3}$, and gaseous hydrocarbons formed during the reaction. For all the configurations, $\mathrm{H}_{2}$ consumption is within a close range $(401 / 1 \pm 0.2)$ indicating no significant hydrogen consumption increase for the reactivated catalyst. Globally, all the analyses tend to show that reactivated catalysts do not have unbalance selectivity and that the ULSD products have very similar properties and quality whatever the quantity of reactivated catalyst used and even in the presence of a NiMo layer. However, it should be noted that the catalyst supplier, Albemarle, forecasts $+1.5 \%$ and $+3 \% \mathrm{H}_{2}$ consumption increase, respectively for configuration $\# 2$ and $\# 3$, compared to the reference configuration. This slight hydrogen consumption increase, coming from a stronger hydrogenation activity of the reactivated catalysts, would be within our analytical standards deviation for most of our analysis and could explain why it is not observed experimentally. Increased hydrogenation activity of reactivated catalyst could be explained by a slightly uncomplete conversion of the spent catalyst active sites to "Type II" during the rejuvenation process. According to the latest findings, DDS pathway happens at both edges (rim) and base plane ("brim") sites of the sulfided CoMo/NiMo nanostructures through a perpendicular $\sigma$ bond with the sulfur atom $[4,24]$. On the other hand HYD pathway (and

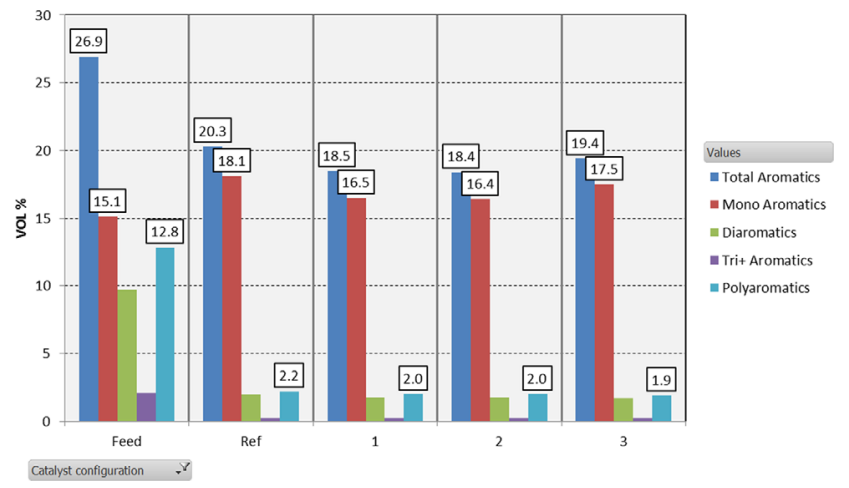

Fig. 8. Comparison of the aromatic content and distribution (weight \%) between the test feed and the different tested catalyst configurations.

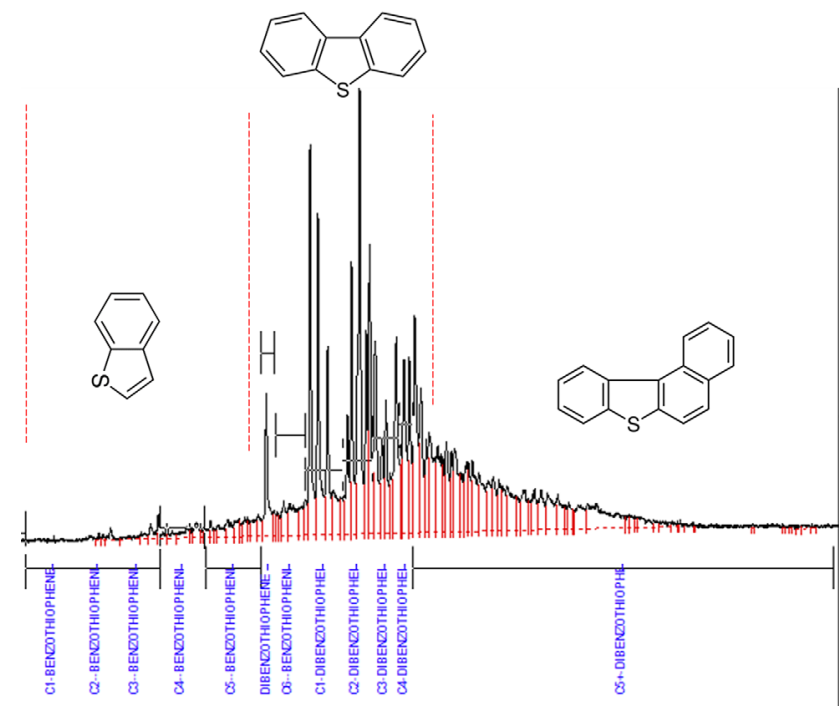

Fig. 9. Sulfurs speciation of the HGO feed used for the pilotplant experiment (GC-SCD signal). "CX" indicates the degree of alkylation of the related structure.

hydrogenation), is restricted to the "brim" sites on top of the crystalline active phase through a horizontal $\pi$ interaction of the aromatic moiety with the base plane. "Type II" HDS active phase, having a higher degree of stacking, will proportionally have less planes available for $\pi$ interactions than "Type I" active sites. Therefore, it can be expected that if the active phase stacking degree of a reactivated catalyst is slightly lower than its fresh counterpart, the DDS/HYD balance maybe affected towards HYD pathway. The lower the stacking degree, the higher the hydrogenation activity.

Finally a particular attention is given to the stacked CoMo-1R/NiMo-1R/CoMo-1R (50/25/25) reactor. This $100 \%$ fully reactivated configuration performs significantly better than a full fresh CoMo reactor $\left(\Delta T=-2{ }^{\circ} \mathrm{C}\right)$. NiMo catalysts are known to have a stronger HYD activity, essential to remove refractory sulfurs. When looking at the feed composition in details (Fig. 9), a majority of poly-alkylated dibenzothiophene and even heavier benzonaphtothiophene 


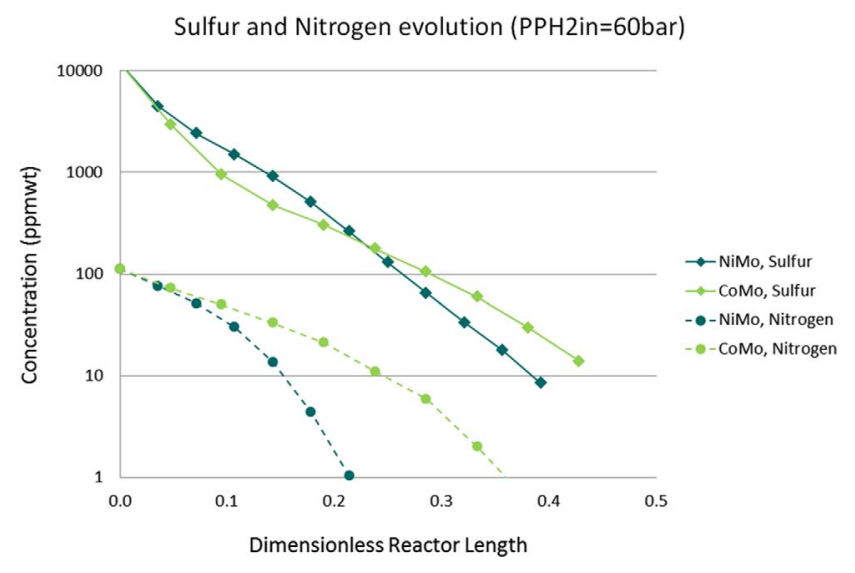

Fig. 10. Difference in activity between NiMo and CoMo on organic sulfur and nitrogen removal along an hydrotreater bed (provided by Albemarle).

can be observed, suggesting that the NiMo layer will help in removing these specific compounds. However, an intermediate sampling reveals that the 1st CoMo layer has removed more than $95 \%$ of the organic sulfurs present in the feed ([S] $<500$ ppm after 1st CoMo-1R layer). What is important, when entering the NiMo layer in the middle of the reactor, is that the sulfurs levels are within the same range as of the organic nitrogens (200 ppm). The latter are strong inhibitor of HDS and known to be preferentially removed through HYD pathway $[9,10]$. Therefore, at this location in the reactor, the NiMo layer with a strong HYD activity, acts mostly on accelerating organic nitrogen removal. This alleviates the competition with organic sulfurs and consequently, facilitates the removal of more bulky sulfurs compounds at the end of the reactor. It is also nicely illustrated in Figure 10 provided by Albemarle and showing the difference between a Co and Ni promoted HDS catalyst for both organic sulfurs and nitrogen removal. In the first part of the reactor, CoMo catalyst is more active than the NiMo thanks to its stronger DDS pathway effective on non-sterically hindered organic sulfurs. But when the [S] reach a concentration in the range of the organic nitrogen, NiMo catalyst will remove faster the nitrogen, allowing to reach 10 ppm [S] before the CoMo catalyst.

\section{Conclusion}

Independent ARRC pilot-plant testing of different catalyst configurations has shown excellent performances of Albemarle REACT ${ }^{\mathrm{TM}}$ catalysts (CoMo \& NiMo). In our case large quantity of reactivated catalyst could be reutilized in the commercial unit, processing the same feed, during the expected 48 month cycle length and producing the same $10 \mathrm{ppm}$ diesel quality. Experimental results were supported by simulations provided by the catalyst supplier. Having a layer of NiMo, in between the CoMo, even both catalysts being reactivated, could significantly reduce the reactor temperature compared to a full fresh CoMo configuration. The NiMo layer acts by accelerating the removal of competing organic nitrogen when sulfurs reach lower concentrations in the second part of the hydrotreater bed. No clear trend in terms of aromatic content, $\mathrm{H}_{2}$ consumption and distillate yields have been observed experimentally when increasing the amount of reactivated catalyst, indicating very similar selectivity of the reactivated catalyst compare to the fresh counterpart. However, according to Albemarle a slight increase in hydrogen consumption may be expected when having large quantities of reactivated catalyst. This hydrogenation activity increase can be attributed to a small loss of active phase stacking degree during the rejuvenation process, altering the DDS/HYD active sites balance (edges vs base planes). Considering the price of reactivated catalysts being $50 \%$ of the fresh and taking into account the $5 \%$ CoMo left-over in the refinery inventory, these scenarios could potentially lead to savings between 30 and $55 \%$ on the catalyst cost for the next hydrotreater load, without impacting the cycle length or the product quality. Bearing in mind the volumes of HDS catalyst in a refinery, this type of approach could potentially help refiners to improve their profitability and margins.

Acknowledgments. The authors would like to thank the following ARRC staff for their continuous support and advises: Ms. Shaima Khalifa, Mr. Abraham George, Ms. Noura Al Kaabi, Mr. Nagesh Babu, Mr. Adel Al Hamadi and Ms. Salama Al Marzooqi.

\section{References}

1 Marafi M., Stanislaus A. (2008) Spent catalyst waste management: A review. Part I-Developments in hydroprocessing catalyst waste reduction and use, Resour. Conserv. Recy. 52, 859-873.

2 Marafi M., Stanislaus A. (2008) Spent catalyst waste management: A review. Part II. Advances in metal recovery and safe disposal methods, Resour. Conserv. Recy. 53, $1-26$.

3 Eijsbouts S., Battiston A.A., van Leerdam G.C. (2008) Life cycle of hydroprocessing catalysts and total catalyst management, Catal. Today 130, 361-373.

4 Stanislaus A., Marafi A., Rana M.S. (2010) Recent advances in the science and technology of ultra low sulfur diesel (ULSD) production, Catal. Today 153, 1-68.

5 Bruneta S., Meya D., Perot G., Bouchyb C., Diehlb F. (2005) On the hydrodesulfurization of FCC gasoline: a review, Appl. Catal. A-Gen. 278, 143-172.

6 Song C. (2003) An overview of new approaches to deep desulfurization for ultra-clean gasoline, diesel fuel and jet fuel, Catal. Today 86, 211-263.

7 Infantes-Molina A., Romero-Pérez A., Mérida-Robles J., Jiménez-López A., Rodríguez- Castellón E., Eliche-Quesada D. (2012) Transition metal sulfide catalysts for petroleum upgrading - Hydrodesulfurization reactions, hydrogenation, in: Karamé I. (ed.), InTech.

8 Egorova M., Prins R. (2004) Competitive hydrodesulfurization of 4,6-dimethyldibenzothiophene, hydrodenitrogenation of 2-methylpyridine, and hydrogenation of naphthalene over sulfided $\mathrm{NiMo} / \gamma-\mathrm{Al}_{2} \mathrm{O}_{3}$, J. Catal. 224, 278-287.

9 Prins R., Egorova M., Rothlisberger A., Zhao Y., Sivasankar N., Kukula P. (2006) Mechanisms of hydrodesulfurization and hydrodenitrogenation, Catal. Today 111, 84-93. 
10 Lauritsen J.V., Kibsgaard J., Olesen G.H., Moses P.G., Hinnemann B., Helveg S., Nørskov J.K., Clausen B.S., Topsøe H., Lægsgaard E., Besenbacher F. (2007) Location and coordination of promoter atoms in $\mathrm{Co}-$ and $\mathrm{Ni}$ promoted $\mathrm{MoS}_{2}$-based hydrotreating catalysts, J. Catal. 249, 220-233.

11 Hensen E.J.M (2000) Hydrodesulfurization Catalysis and Mechanism of Supported Transition Metal Sulfides, $P h D$ Thesis, Technische Universiteit Eindhoven, 12-17.

12 Huang T., Jundong Xu, fan Y. (2018) Effect of concentration and microstructure of active phase on the selective hydrodesulfurization performance of sulfide $\mathrm{CoMo} / \mathrm{Al}_{2} \mathrm{O}_{3}$ catalysts, App. Catal. B: Env. 220, 42-56.

13 Dufresne P. (2007) Hydroprocessing catalysts regeneration and recycling, Appl. Catal. A-Gen 322, 67-75.

14 Eijsbouts S., Plantenga F., Leliveld B., Inoue Y., Fujita K. (2003) STARS and NEBULA - New generations of hydroprocessing catalysts for the production of ultra low sulfur diesel, Prepr. Pap.-Am. Chem. Soc. Div. Fuel Chem. 48, 2, 494.

15 Marafi M., Kam E.K.T., Stanislaus A., Absi-Halabi M. (1996) Rejuvenation of residual oil hydrotreating catalysts by leaching of foulant metals: modelling of the metal leaching process, Appl. Catal. A-Gen 147, 35-46.

16 Mederos F.S., Ancheyta J., Chen J. (2009) Review on criteria to ensure ideal behaviors in trickle-bed reactors, Appl. Catal. A-Gen 355, 1-19.

17 Henry C.H., Gilber J.B. (1973) Scale up of pilot plant data for catalytic hydroprocessing, Ind. Eng. Chem. Process Des. Dev. 12, 3, 328-334.
18 Yokoyama Y., Ishikawa N., Nakanishi K., Satoh K., Nishijima A., Shimada H., Matsubayashi N., Nomura M. (1996) Deactivation of $\mathrm{Co}-\mathrm{Mo} / \mathrm{Al}_{2} \mathrm{O}_{3}$ hydrodesulfurization catalysts during a one-year commercial run, Catal. Today 29, 261-266.

19 Takana Y., Shimada H., Matsubayashi N., Nishijima A., Nomura M. (1998) Accelerated deactivation of hydrotreating catalysts: comparison to long-term deactivation in a commercial plant, Catal. Today 45, 319-325.

20 Venkatesh R.P., Bhaskar M., Sakthivel S., Selvaraju N., Velan M. (2010) Pilot Plant studies on accelerated deactoivation of commercial hydrotreating catalyst, Petr. Sci. Technol. 28, 93-102.

21 Schuman S.C., Shalit H. (1971) Hydrodesulfurization, Catal. Rev. 4, 245-318.

22 Yang H., Briker Y., Szynkarczuk R., Ring Z. (2004) Prediction of density and cetane number of diesel fuel from GCFIMS and PIONA hydrocarbon composition by neural network, Prepr. Pa.-Am. Chem. Soc, Div Fuel. Chem. 49, $1,81-83$.

23 Qian Y., Qiu Y., Zhang Y., Lu X. (2017) Effect of different aromatics blended with diesel on combustion and emission characteristics with a common rail diesel engine, App. Therm. Eng. 125, 1530-1538.

24 Lauritsen J.V., Kibsgaard J., Olesen G.H., Moses P.G., Hinnemann B., Helveg S., Nørskov J.K., Clausen B.S., Topsøe H., Lægsgaard E., Besenbacher F. (2007) Location and coordination of promoter atoms in $\mathrm{Co}-$ and $\mathrm{Ni}$ promoted $\mathrm{MoS}_{2^{-}}$ based hydrotreating catalysts, J. Catal. 249, 220-233. 